\title{
The Concept and Consensus of Building Public Space
}

\author{
Ying Shi ${ }^{1, a}$, Ying Chang ${ }^{2, b}$ \\ ${ }^{1}$ School of Architecture, South China University of Technology; State Key Laboratory of Subtropical \\ Building Science, South China University of Technology, Guangzhou, Guangdong, China \\ ${ }^{2}$ School of Architecture, South China University of Technology, Guangzhou, Guangdong, China \\ aworksy2004@126.com, b974915134@qq.com
}

\begin{abstract}
Keywords: Building Public Space;POPS;Urban Open Space;accessibility
Abstract The booming city gradually tend to be model and commercialization, the privatization of the construction management results in the interests has been the main body of all the space. After summing up the successful experience of New York in POPS, through the practice and theory summary of China's privately owned public space, this paper put forward the concept of "building public space", and hoping to provide a unified standard for the future research in this field.
\end{abstract}

\section{Introduction}

Under the violent capitalists operation, the social resources which are free open to public had been their tools to make money. After half a century of urban practice, western countries implement a set of comprehensive POPS regulations to guide the developer of urban construction behavior, and has a high degree of public participation. In recent years, POPS construction mechanism was introduced to China, metropolis have pay more attention to the "building public space", but the understanding of building public space did not form a clear concept, classification and the description of nature in the privately. There is no research in the field of privately public space in China.

\section{The Present Situation of Open/Public Space in China}

Current Chinese cities, urban space forms related to shopping and business emerge in large numbers so that limited land is used for commercial development, which the open space for masses is quantity shortage and poor quality ${ }^{[1]}$.

Quantity Shortage The existing 24-hour open space is usually a government-provided project, but the number is limited, can not meet the use of all citizens. For example, the provisions of road indicators for $8 \%$ to $15 \%$, while the proportion of urban roads is usually more than $20 \%{ }^{[2]}$.

Poor Quality Poor Accessibility: Most of the beautiful environment and complete facilities space just open to their customers, time can not meet the all-weather open. In 2016 the state promulgated a file that pointed out that no longer build a closed residential quarters, built quarters have to open to promote land conservation, which promote the privatization of private space.

Low Atmosphere: China's current open space is just as a short break and view of the residents, which is lack of atmosphere and infrastructure that inspires all masses to communicate information spontaneously. Class consciousness causes differences in use.

Culture Missing: Square is a particular public space in Europe, which is used to hold religious activities. But Chinese traditional public space is street that is closely related to our city life, such as neighborhood unit which is our traditional social model. Therefore, urban space development should respect its regional culture.

The problem of urban open space discussion promote the development of private building public issues, half a century, the concept of foreign private public space has a clear definition and a perfect regulatory system, which has a good reference for the beginning of China in this issue. 


\section{The Definition of Building Public Space at home and abroad}

The concept abroad "Privately Owned Public Spaces" was originally proposed by Jerold S. Kayden, a professor at Harvard University ${ }^{[3]}$. Since then, a number of cities at home and abroad have made a definition of the type of public space through their laws and regulations.

Privately Owned Public Space (POPS) in New York: the property owners/developers provide, build and maintain a space that open to the public, can be exchanged for extra award building area. Privately Owned Public Open Space (POPOS) in San Francisco: refers to the private development and management of the public can enter and exit the space. Open Space in Taiwan: the construction base in accordance with the provisions of the set up to a certain size and connected roads for the passage or open space. Public Open Space in Private Development (POSPD) in Hong Kong: open space which is privately managed and accessible to the public in and out of the private property.

These concept not only provide an important reference for the Chinese study of private owned public space, but also provide technical support for urban construction.

Chinese Research Status There are differences about the definition in China, and the direction of research is diverse. First, the "urban" of building public space. Yang Jing wrote the first study of urban and architectural links. Fei Lan analyzed urban complex external public space role, then refining the "urban" specific to create strategies and methods ${ }^{[4]}$.

Second, research on the design of building public space, such as research on the space attribute of combination with architectural function. The research findings are mainly concentrated in the South China University of Technology, Chongqing University and Tianjin University.

Third, on the construction of public space planning system research. Sun Tongyu proposed the concept of building-oriented urban public space model.

In most cases, China still does not have a specific concept of public space. Although the definition of public space is very vague in China, their essence is the same.

\section{Definition of Public Space in Buildings in view of National Conditions}

Unlike the concept of Privately Owned Public Space, the architectural public space mentioned in this paper is based on the context of urban planning management in China. Building Public Space refers to the construction site for all public, 24 hours a day for use and holding activities. The scope of space covers both public ownership and private development. The Building Public Space is not only an integral part of the building open space, but also has the functions of urban open space. "Public" has become the main criterion for judging the quality of public space, and distinguishes public space from open space. The scope of the study of Building Public Space is the combination of exterior and interior building entities and space. If a building provides masses places to easy to pass or to get in or have a rest, it can be put into the scope of the study.

Open Space and Public Space Conventional urban open space emphasizes its open state ${ }^{[5]}$. We can think that "Building Public Space" is consistent with the properties of urban open space, which has a unified public sphere, namely, urban open space is equal to the building public space. For example, in the B-type commercial service facilities, a commercial building through the building back line set the entrance of the square space, the use of land belongs to the land units, while the right to use the space belongs to the masses. Space, even within the construction site outside the $G$ class, as long as the right to use the space belongs to the public, to provide public facilities and allow the occurrence of public life, which is subordinate to the general scope of urban open space. We named this kind of urban open space as the "Building Public Space".

\section{The Nature of Biulding Public Space}

In the study of the "public" architectural public space, the building public space to eliminate the "public" concept of confusion, the word is more accurate. The building public space is an integral part of the urban spatial system and an integral part of the building itself. It also has the dual attribute and double space function of the building space and the urban space. 
Identity Default: the Whole Masses "Urban Open Space" refers to urban areas of protected or conserve land on which development is indefinitely set aside, which areas left open for the use of the masses, such as a piazza, plaza, park and courtyard. But the common open space we are exposed to is not open to whole population, such as many buildings' open space have entry requirements, such as in formal wear, unilaterally rejected the vast majority of the crowd, is a "veritable" public space. Therefore, the identity of the public space does not exist the default situation, the face of all the public, including beggars. Arcade Street in the night after the closure of the shop, the corridor in addition to taking into account the city wind corridor, or begging staff rest shelter.

Time Default: 24 Hours a Day The time limit for the opening of the building has led to the opening time of the building public space is presupposed. Building public space should not be an obstacle to public use because of closure, 24 hours a day to ensure open is the most basic protection, and is also the main factor different from other urban open space.

Behavior Default: High Accessibility Physiological accessibility: In order to meet the characteristics of full-time, there is still directly outside the entrance, channel space or square after building closed, which is the necessary conditions to meet the physiological accessibility. For example, the type of POPS in New York, including the roof-type walking space, the underlying overhead space, direct access to the subway station floor elevator and other open area, to meet the full physiological accessibility conditions. Psychological accessibility: Most of the practices mentioned in the public space are big squares full of conspicuous political behavior, this space has a very low availability before sunset. European square has a symbolic meaning because of the nearby church, a strong symmetry keep a good distance from masses, leading to poor mental accessibility that is bad for the construction of the building public space. The space of appropriate scale and sunshade component can assume the public communication.

Diversity of Activities For the owner of the space, it reflected in the functional diversification. Owners allow the development of business, entertainment, exhibitions, sightseeing and other functions with the space function. For space users, the diversity is reflected in the type of activities. As long as the legitimate circumstances, the user unrestricted to choose their own leisure, walking, entertainment, neighborhood exchanges or any other activities to enjoy the space.

Territoriality Building public space should respect the local historical context and environmental climate, so that can make a appropriate space type, such as arcade architecture. This special public space full of private property. If you watch a Hong Kong film, you will find landlords, independent arcade for own or pavement rental, cohabitation of the market bring a thinking of life better than rough intervention by municipal planning department.

\section{The type of Biulding Public Space}

There are six common forms of the space according to their location:

Plaza Include residential plaza, elevated plaza, underground concourse, sunken plaza, which are used for residents hold activities spontaneously.

Arcade Include covered arcade, through block arcade, entrance porch area, which is used for passage conveniently without sunshine and rain, or other spontaneous use.

Thoroughfare/Sidewalk Include covered pedestrian space, subway access areas, pedestrian circulation space, through block public passage, bottom overhead space, which is used for pass through and be traffic arteries.

Public/Commercial Utilities Include stair/escalator/elevator, shopping arcade, restrooms, public lobby, which often with business activities such as retail, snack bar and open-air coffee bar.

Green Include courtyard, landscaped open area/space, landscaped terrace plaza, which space is exist in the cracks between two buildings, enjoy the part of the shadow that bring from building.

Public Display Include public exhibit space, visual residual, commons and public areas, which is use for free display art works to public, including sculpture, accessorial building, painting, etc.That is an important window to show city environment and the dissemination of art information.

Therefore, the building public space has a double space function: building space function with the general building public space for the building within the user transport evacuation, activities, 
communication responsibilities. At the same time, it can bear the responsibility of urban open space, such as supporting urban traffic space to relief the traffic pressure and provide a daily activity place. Double space function is an important criterion for judging if the space is a building public space.

\section{Summary}

The formation and consensus of the concept of building public space is another achievement of urban open space division. The refinement of the space type has important significance to the construction, management and maintenance of space, which is beneficial to bring building public space into urban planning. It is convenient to put forward the design control and control frame with the design guideline as the starting point, and form the control system of public space design which is easier to operate and implement. In addition, the division of ownership and public use as a source of building public space concept, including private owners and all masses, participating in the design is also the core of human city construction.

\section{References}

[1] John Lund Kriken, Philip Enquist and Richard Rapaport, in: City Building: Nine Planning Principles for the Twenty-Fist Century[M]. Jiangsu People's Publishing House,2013,7:4-7.

[2] Tongqing Song, Xigang Zhu, Weixuan Song. [J]. City Planning Review, Vol.36.NO.5 May (2012),p.66

[3] Information on http://apops.mas.org/about/history/

[4] Fei Lan, Research on the Design of Urban Complex Exterior Public Space Based on the Perspective of Urbanity in Chinese, [D].South China University of Technology (2015)

[5] Chen Zhu, Ye Min. Urban Planning International. Vol.24.NO.3 (2009),p. 44 